\title{
Causal Time Loops and the Immaculate Conception
}

\author{
Jeremy W. Skrzypek \\ University of Mary
}

\begin{abstract}
The doctrine of the immaculate conception, which is a dogma binding on all Roman Catholics and also held by members of some other Christian denominations, holds that Mary the mother of Jesus Christ was conceived without the stain of original $\sin$ as a result of the redeeming effects of Christ's later life, passion, death, and resurrection. In this paper, I argue first that, even on an orthodox reading of this doctrine, the immaculate conception seems to result in a kind of causal time loop. I then consider several common philosophical objections to causal time loops, showing how each is either not a serious problem for causal time loops in general or is not a serious problem for the immaculate conception time loop in particular because of some particular features of that particular loop. The upshot of this discussion is that it shows that anyone who is committed to the dogma of the immaculate conception is also committed to the possibility, and, indeed, the actuality, of at least one causal time loop, but also that this is no reason to reject the dogma, since all of the major worries for causal time loops can be resolved in one way or another.
\end{abstract}

\section{Introduction}

A causal time loop is a state of affairs in which some later event is at least a partial cause of some earlier event which is also at least a partial cause of the later event. ${ }^{1}$ Such a state of affairs is called a causal time loop because in such a state of affairs the direction of causality loops back on itself. Within such a state of affairs, each event

\footnotetext{
${ }^{1}$ Here and throughout, following contemporary parlance, I will speak of causal time loops as involving causal relations between events, but these formulations can also be translated into the language of substance or agent causation without any significant loss of meaning. In such case, each 'event' can be understood as a state of affairs in which some particular substance or agent exercises its causal powers to bring about some other state of affairs involving the same or some other substance or agent (in which the substance or agent is either brought into existence or comes to possess or lose some particular property). This will be especially important to keep in mind as we look at sources and texts that work within an Aristotelian metaphysical framework rather than the Neo-Humean approach popular in contemporary discussions.
}

Journal of Analytic Theology, Vol. 8, August 2020

10.12978/jat.2020-8.0904-65181010

(C) 2020 Jeremy W. Skrzypek • (C) 2020 Journal of Analytic Theology 
causes the other event which in turn causes it, with the result that each event is both the cause and the effect of the other, each depending on the other for its own existence. $^{2}$

There are at least three possible types of causal time loops. The most commonly discussed type of causal time loop is one involving time-travel: someone or something travels back in time to cause some earlier event that in turn causes some later events, among which are the travelling back in time of the original person or thing. ${ }^{3}$ A second possible type of causal time loop involves not some particular person or thing but the whole of time itself: on this model, time itself travels in a loop, looping back on its own tail like the ouroboros, such that the "end" of the universe's timeline is also its "beginning." There is also a third possible type of causal time loop, which involves neither time travel nor the whole of time looping back on itself. This sort of causal time loop can be constructed by granting the existence of some causal agent existing in eternity, something or someone that has equal and simultaneous access to events at several times. In such case, either the causal efficacy of the later event could "run through" the causal efficacy of the eternal being to the earlier event, or the causal efficacy of the eternal being could "run through" the causal efficacy of the later event and back through eternity to the earlier event. ${ }^{4}$

Note that in all three possible types of causal time loops, the causal loop can involve either direct causal relations or indirect causal relations. A causal time loop involving direct causal relations would be one in which the later event directly causes the earlier event and the earlier event directly causes the later event. For example, someone might travel back in time and perform certain actions such that one turns out to be, as a result of those actions, one's own mother or father..$^{5}$ In such case one turns out to be the direct cause of one's own existence. Most often causal time loops are cases that involve indirect causal relations: the later event is at least a partial cause in a causal series which ultimately results in the earlier event and the earlier event is at least a partial cause in a causal series which ultimately results in the later event. For example, someone might travel back in time and perform certain actions

\footnotetext{
${ }^{2}$ For excellent introductions to the various issues surrounding causal time loops see Hanley (2004) and Wasserman (2018, Chapter 5). Causal time loops are also discussed in Lewis (1976), Macbeath (1982), Nahin (2017, 214-229), Meyer (2012), and Smith (2018).

${ }^{3}$ Such causal time loops are common plot devices in science fiction. In the 1984 film, The Terminator, for example, one of the main characters, Kyle Reese, is sent back in time by John Connor to protect John's mother Sarah from a murderous robot sent from the future. While in the past, Reese has sexual relations with Sarah Connor which results in Sarah conceiving and bearing a child, who turns out to be John Connor. Kyle Reese, then, turns out to be John Connor's father all along (though it is unclear whether John knows this). Causal time loops serve as important plot devices in other science fiction films as well, such as Terminator 2: Judgment Day, Somewhere in Time, Bill and Ted's Excellent Adventure, La Jetée, 12 Monkeys, Harry Potter: Prisoner of Azkaban, Looper, Primer, Project Almanac, Timecrimes, Triangle, Predestination, and Interstellar, among others.

${ }^{4}$ Importantly, the eternal being would not necessarily have to be divine. Christopher Nolan's 2014 film, Interstellar, for example, features a human being who comes to possess, at least for a time, simultaneous access to several moments in time, including ones in his own past.

${ }^{5}$ See, for example, Robert A. Heinlein's short story, "-All You Zombies-" (Heinlein 1999) and the 2014 film adaptation, Predestination, in which the main character, through a complicated series of events, turns out to be both his own mother and his own father. For a helpful discussion of self-parenting causal time loops, see Hanley $(2014,139-141)$.
} 
which cause one's own parents to meet and fall in love, which causes them to later marry, which causes them to later conceive the child who will eventually travel back in time. ${ }^{6}$ In such case one turns out to be the indirect cause of one's own existence.

Causal time loops should be distinguished from causal time paradoxes. A causal time paradox is a state of affairs in which someone or something travels back in time and changes or eliminates some event which is already a part of that person or thing's own causal history. ${ }^{7}$ Causal time paradoxes, such as the grandfather paradox, are paradoxical precisely because they are impossible. One cannot go back in time and kill one's own grandfather in his youth, because that would mean that at least one of one's parents were never born, which would mean that the time-traveler herself was never born, which, of course, makes it impossible for her to travel back in time, since she would never have existed. Causal time loops, on the other hand, while they may elicit suspicion or perplexity, are not paradoxical: they are not impossible by virtue of being contradictory. A causal time loop is not a state of affairs in which one event contradicts or makes impossible the existence of some other event. On the contrary, a causal time loop is, as will be shown below, a logically consistent state of affairs in which two events occurring at two different times mutually depend on one another for their existence.

In this paper, I explore a particular causal time loop of the third variety present in the Christian tradition: the immaculate conception. The immaculate conception, which is a dogma binding on all Roman Catholics and also held by members of some other Christian denominations, holds that Mary the mother of Jesus Christ was conceived without the stain of original sin as a result of the redeeming effects of Christ's later life, passion, death, and resurrection. In this paper, I first outline the main elements of this Catholic dogma, arguing that even on a straightforward reading, it seems to result in a kind of causal time loop (though not, it seems, one in involving time travel or the whole of time looping back on itself). I then consider several common philosophical objections to causal time loops, showing how each is either not a serious problem for causal time loops in general or is not a serious problem for the immaculate conception time loop in particular because of some particular features of that particular loop. The upshot of this discussion is that it shows that anyone who is committed to the dogma of the immaculate conception is also committed to the possibility, and, indeed, the actuality, of at least one causal time loop, but also that this is no reason to reject the dogma, since all of the major worries for causal time loops can be resolved in one way or another.

\section{The Immaculate Conception as Causal Time Loop}

In his 1854 papal encyclical Ineffibilis Deus, Pope Pius IX pronounced the following dogma binding on all Roman Catholics:

\footnotetext{
${ }^{6}$ A scenario like this is depicted in the first Back to the Future film.

${ }^{7}$ Like causal time loops, causal time paradoxes are also common plot devices in science fiction. Examples of films involving causal time paradoxes include the Back to the Future series, Looper, X-Men: Days of Future Past, and Terminator: Genisys, among others.
} 
We declare, pronounce, and define that the doctrine which holds that the most Blessed Virgin Mary, in the first instance of her conception, by a singular grace and privilege granted by Almighty God, in view of the merits of Jesus Christ, the Savior of the human race, was preserved free from all stain of original sin, is a doctrine revealed by God and therefore to be believed firmly and constantly by all the faithful. (Pope Pius IX 1854)

The Catechism of the Catholic Church unpacks this dogma as follows:

To become the mother of the Savior, Mary 'was enriched by God with gifts appropriate to such a role.' The angel Gabriel at the moment of the annunciation salutes her as 'full of grace.' In fact, in order for Mary to be able to give the free assent of her faith to the announcement of her vocation, it was necessary that she be wholly borne by God's grace. Through the centuries the Church has become ever more aware that Mary, 'full of grace' through God, was redeemed from the moment of her conception. That is what the dogma of the Immaculate Conception confesses, as Pope Pius IX proclaimed in 1854 . . . The 'splendor of an entirely unique holiness' by which Mary is 'enriched from the first instant of her conception' comes wholly from Christ: she is 'redeemed, in a more exalted fashion, by reason of the merits of her Son.' The Father blessed Mary more than any other created person 'in Christ with every spiritual blessing in the heavenly places' and chose her 'in Christ before the foundation of the world, to be holy and blameless before him in love.' (Catholic Church 1997, Part One, Section Two, Chapter Two, Article 3, Paragraph 2, 490-492)

And in his Fundamentals of Catholic Dogma, Ludwig Ott provides a few more of the metaphysical details of this remarkable series of events:

By conception is to be understood the passive conception. The first moment of the conception is that moment of time in which the soul was created by God and infused into the bodily matter prepared by her parents. The essence of original sin consists in the lack of sanctifying grace, in consequence of the fall of Adam. Mary was preserved from this defect, so that she entered existence in the state of sanctifying grace. Mary's freedom from original sin was an unmerited gift of God, and an exception from the law which was vouchsafed to her only. The efficient cause of the Immaculate Conception of Mary was Almighty God. The meritorious cause was the Redemption by Jesus Christ. It follows from this that even Mary was in need of redemption, and was in fact redeemed. By reason of her natural origin, she, like all other children of Adam, was subject to the necessity of contracting original sin, but by a special intervention of God, she was preserved from the stain of original sin. Thus Mary also was redeemed 'by the grace of Christ' but in a more perfect manner than other human beings. While these are freed from original sin present in their souls, Mary the Mother of the Redeemer, was preserved from the contagion of original sin. Thus the dogma of the Immaculate Conception of 
Mary in no way contradicts the dogma that all children of Adam are subject to Original Sin and need redemption. The final cause of the Immaculate Conception of Mary is her Motherhood of God. (Ott 1992, Book Three, Part 3, Chapter 2, Section 3, Paragraph 1)

From these three sources, we learn several key details about the nature of the immaculate conception. First, we learn that the immaculate conception of Mary is a particular event that takes place at a particular moment in time. The particular moment in time at which this event occurs is the precise moment of Mary's conception, the precise moment at which God creates Mary's soul and infuses it in the matter provided by her parents. What occurs at this precise moment in time is that Mary, the mother of Jesus Christ, is "preserved from the stain of original sin." As a result, there is no moment in time at which Mary can be said to be in a state of original sin; at the precise moment that she comes into existence the original sin that would have been transmitted to her from her parents is also blocked (which seems to imply that had this particular event not occurred, Mary would have been in a state of original sin, like the rest of us, at least for a time).

From these three sources we also learn of another particular event or series of events, this one occurring some time after the first: the redemption of fallen humanity by Mary's son, Jesus Christ, through His life, passion, death and resurrection. And what is most interesting about this later event or series of events for our present discussion is its special relationship to Mary's immaculate conception. While each of the documents cited above is clear that Mary's immaculate conception has as its primary or ultimate cause, the agency of almighty God, each also suggests that Christ's redemption of fallen humanity through His life, passion, death, and resurrection is somehow and in some sense causally efficacious in the bringing about of this event. In Ineffibilis Deus, for example, we are told that almighty God preserves Mary from the stain of original sin "in view of the merits of Jesus Christ." In the Catechism of the Catholic Church, we are told that Mary's redeemed state of grace "comes wholly from Christ." And in the Fundamentals of Catholic Dogma, we are told that the redeeming work of Jesus Christ is the "meritorious cause" of Mary's immaculate conception. So, even though almighty God is Himself the primary or ultimate cause of both the immaculate conception and the redeeming work of Jesus Christ, it seems that, on this doctrine, God somehow accomplishes the immaculate conception through or by means of the actual redeeming work of Christ. In this way, Christ's life, passion, death, and resurrection can be seen as a sort of instrumental or secondary cause of Mary's immaculate conception.

But how or by what mode of causality did the redeeming work of Christ cause Mary's immaculate conception? Once again, in Ineffibilis Deus we are told that almighty God preserves Mary from the stain of original sin "in view of the merits of Jesus Christ." This would seem to suggest that the sort of causality that we are dealing with here is a kind of final causality. It would seem to suggest that Christ's redeeming work is the cause of Mary's immaculate conception only in the sense that God causes Mary's immaculate conception for the sake of and with the knowledge of Christ's later life, passion, death, and resurrection. But notice that the language describing the causal relation between these two events in the later two documents is a bit stronger 
than this. As I pointed out in the previous paragraph, in the Catechism of the Catholic Church, we are told that Mary's redeemed state of grace "comes wholly from Christ", and in the Fundamentals of Catholic Dogma, we are told that the redeeming work of Jesus Christ is not the final but the "meritorious" cause of Mary's immaculate conception. In the latter piece, Ott is very careful to distinguish between the two kinds of causality involved. As he explains, the final cause, the end to which the immaculate conception is directed, is Mary's motherhood of God. But the meritorious cause is Christ's redemption of fallen humanity. Christ's life, passion, death, and resurrection merits or earns for Mary the sanctifying grace that preserves her from original sin. What exactly is this meritorious causality of which Ott speaks? Unfortunately, Ott does not clearly spell out this notion in the text, but I think that it is telling that Ott's discussion of the meritorious cause of Mary's immaculate conception is placed between his discussions of the efficient and final causes. And since the formal cause of Mary's immaculate conception is nowhere mentioned by name in the text, I think that we can plausibly infer that the meritorious cause is meant to be a sort of formal cause. And this would seem to accord well with what is said to have happened to Mary during this particular series of events. Traditionally, sanctifying grace, the sort of grace that Mary is said to have received that allowed her to be preserved from original sin, is understood as operating formally, as a sort of formal cause, reconfiguring the person's will such that he or she is able to love God above all else. ${ }^{8}$ I think that it is plausible, then, to suggest that the causality operative between Christ's redemption of fallen humanity and Mary's immaculate conception is something more than mere final causality (though it most certainly is that as well). It is also at least an instance of formal causation involving sanctifying grace. (Whether it is also an instance of efficient causality cannot I think be ruled out, though there is much less evidence for that.)

So far, then, we have explored the basic "soteriological mechanics" of the immaculate conception as expressed in the texts above. What I would like to show now is that, based on the key claims we have thus far investigated, we should conclude that, even on a straightforward reading of the doctrine, the immaculate conception is indeed a kind of causal time loop. Recall our earlier characterization of causal time loops. A causal time loop is a state of affairs in which some later event is at least a partial cause of some earlier event which is also at least a partial cause of the later event. In the case of the immaculate conception, the earlier event is the event of the immaculate conception, the particular event in which Mary is preserved at the moment of her conception from the stain of original sin. The later event is the redemption of fallen humanity by Jesus Christ through His life, passion, death, and resurrection. What is clear from the three sources cited above is that the later event, the redemption of fallen humanity by Jesus Christ through His life, passion, death, and resurrection, is somehow, and in some sense, the cause of Mary's immaculate conception, an earlier event. As I argued above, even if God is the primary or ultimate cause of both events, it seems that God has caused the earlier event through or by means of the later event. It also seems clear that, in this series of events, the earlier event, the immaculate conception, is also a partial, indirect cause of the later event,

\footnotetext{
${ }^{8}$ See, for example, Stump (2003, Chapter 13).
} 
the redemption of fallen humanity by Jesus Christ though His life, passion, death, and resurrection. The event of Mary's immaculate conception is at least a partial cause in a causal series (which also includes Mary's annunciation and her conceiving and giving birth to her son Jesus Christ) which ultimately results in His passion, death, and resurrection. And so what we have in the immaculate conception is, I think, a clear case in which some later event is at least a partial cause of some earlier event which is also at least a partial cause of the later event. Christ's redemption of fallen humanity causes the earlier immaculate conception of His mother, Mary, and the immaculate conception of Mary is an integral cause in a causal series which culminates in the later redemption of fallen humanity by her son, Jesus Christ. In such case, as in other causal time loops, each event appears to be both the cause and the effect of the other. Both events seem to mutually depend on one another for their own existence.

But what sort of causal time loop are we dealing with here? If the events of the immaculate conception do indeed constitute a causal time loop, it would seem that it would have to be a causal time loop of the third variety, that which makes use of a causal agent existing in eternity (in this case the causal agent existing in eternity is God). Earlier I suggested that there are two ways in which the direction of causality may proceed in such a loop: either the causal efficacy of the later event could "run through" the causal efficacy of the eternal being to the earlier event, or the causal efficacy of the eternal being could "run through" the causal efficacy of the later event and back through eternity to the earlier event. The first proposal would seem to violate God's impassibility, as it would require that God's causing of the earlier event be caused by the occurrence of the later event. And so I think that if we wish to preserve God's impassibility we should try to understand the immaculate conception causal time loop according the second proposal. On this model, God causes the later event, Christ's redemption of fallen humanity by means of His life, passion, death, and resurrection, and through or by means of this later event, God also causes the earlier event, the preservation of Mary from the stain of original sin, which event, in turn, serves as a partial, indirect cause of the later event. Understood in this way, the direction of causality in this series of events would indeed travel in a loop. From eternity God causes both events in such a way that each causes the other, the causality of the earlier event passing through time to the later event, and the causality of the later event passing through eternity to the earlier event.

Now, usually causal time loops are understood as constituted by relations of efficient causality or something very much like it, but in this case at least one of the causal relations, the causal relation between Christ's redemption of fallen humanity and Mary's immaculate conception, appears to be of the formal causal variety (though, as I have suggested, it may also be of the efficient causal variety, but there is much less evidence for that claim). How big of a difference does this make? If the causal relation between Christ's redemption of fallen humanity and Mary's immaculate conception were merely of the final causal variety, then perhaps there would be a causal loop here, but it would not be a terribly interesting one. That some later event could cause some earlier event by serving as its final cause would not be particularly surprising. That is precisely how final causality is supposed to work. But that some later event could cause some earlier event as its formal or efficient cause is much more interesting. And that is what we have in the case of the immaculate 
conception. As a result, I think that the state of affairs comprising the immaculate conception does indeed constitute a kind of causal time loop, one that is structurally similar to the sorts of causal time loops proposed and puzzled over in the contemporary literature and worth investigating further as such.

\section{Four Concerns for Causal Time Loops}

If I am right in understanding the immaculate conception as a kind of causal timeloop, does this give us an additional reason to be suspicious of or to reject this doctrine? I think that it does not. And in order to defend the claim that it does not, I would now like to consider and address four common philosophical concerns for causal time loops. What I hope to show is that if there is some reason to be suspicious of or to reject the dogma of the immaculate conception, it is not because it is a causal time loop.

\section{A. The Future is Real}

The first concern for causal time loops that I would like to consider is that causal time loops seem to require a commitment to an eternalist conception of time, according to which all times, the past, the present, and the future, all exist. Causal time loops seem to require an eternalist conception of time for the following reason: in order for a future event to cause some earlier event it would seem that it must exist, at least in some sense. Given that the future event is already a part of the earlier event's causal history, it must in some sense already be true that the future event is occurring or has occurred. Importantly, this would not require the further claim that the past, present, and future all exist in the same way. There may still be something special or privileged about the present, perhaps pertaining to the way in which it exists. But it seems that future events would have to exist in some sense in order to be causally efficacious.

My reply to this concern is to admit that by granting the existence of causal time loops one does seem to be committed to an eternalist conception of time, and by understanding the immaculate conception as a sort of causal time loop, this will commit those who adhere to this doctrine to the actual existence of future events. But I would also like to suggest that this is something to which those who do hold or would hold such a doctrine may already be committed. In order to properly orchestrate the series of events that constitute the immaculate conception, it seems that God would either have to orchestrate them from the perspective of eternity or otherwise have knowledge of those events in the series that, from the perspective of the earlier events, are in the future. Now, it seems to me that anyone who is already committed to the claim that God is eternal and sees the whole of time from that perspective is committed to the claim that the past, present, and future all exist. For if God really does "see" the future, then the future must be there for Him to see. Moreover, anyone who is already committed to the claim that God has infallible foreknowledge would seem to be committed the existence of those future events which God knows will 
occur. For if God really does know which events will occur, then those events that will occur must be there for God to know them. Otherwise there would be no proper object of God's knowledge. There would be nothing for Him to know. And so while it seems that admitting the existence of causal time loops commits one to an eternalist conception of time, this should not be seen as a problem for those who would hold the doctrine of the immaculate conception, since they should probably already be committed to this claim for other reasons. ${ }^{9}$

\section{B. Freedom Undermined}

The second concern for causal time loops that I would like to consider is that causal time loops seem to undermine the freedom of any causal agents that exist and act within them. ${ }^{10}$ It seems that because their future actions are also already a part of their own causal histories, causal agents existing and acting within causal time loops cannot but act as they do. A clear example of this is the grandfather paradox. If one were to travel back in time and attempt to kill one's own grandfather in his youth, the nature of causal time loops dictates that this person cannot in fact accomplish her goal. The time-traveler is not free to kill her own grandfather in his youth because it is already a part of that person's own causal history that her grandfather lived long enough to conceive that person's mother or father. Logical consistency demands that whatever the time-traveler ends up doing in the past, she will find out that she had always failed to kill her own grandfather, that he has always already survived her attempts to end his life. Even more than that, it seems that every decision or action made by the time-traveler is fixed because every decision or action is already a part of that person's own causal history. She is already a product, either directly or indirectly, of those particular decisions and actions. The world in which the person was raised from her youth already owes at least some of its particular features to the particular actions and decisions of her time-travelling self. Any actions or decisions that the time-traveler performs while in the past are already built into her own history, are already built into the loop. ${ }^{11}$

\footnotetext{
${ }^{9}$ Which is not to say that everyone committed to the eternality or perfect foreknowledge of God does in fact accept eternalism. I make no claims here about what such thinkers do or have actually held about the nature of time. I mean only to report that a commitment to God's eternality or God's perfect foreknowledge seems to entail a commitment to the existence of future events, and so that the dogma of the immaculate conception might also entail such a commitment should not be uniquely alarming to those authors. For a similar argument in support of the sort of entailment that I am suggesting here, see: Alexander Pruss, "Grace and Theories of Time", available at http://alexanderpruss.blogspot.com/2019/06/grace-and-theories-of-time.html (Jun., 2019).

${ }^{10}$ See, for example, Rea (2015), and the relevant works cited therein, as well as Wasserman (2018, Chapter 4).

${ }^{11}$ Indeed, as Rea (2015) points out, it seems that the actions and decisions of all agents existing and acting within causal time loops are fixed for the same reason. For the time-traveler who has returned from the future is already a product of the particular actions and decisions that those agents are performing and will perform. Those particular actions and decisions are already built into the timetraveler's loop.
} 
In the case of the immaculate conception, this is just as true as in any other causal time loop. At the annunciation, Mary is said to have assented to God's plan to have her conceive and bear His son, Jesus Christ. But could Mary have freely chosen not to assent to that plan? It seems not, for at the annunciation it is already true of Mary that she has in fact been immaculately conceived, and her immaculate conception, as we have seen, has come about as a result of her son's later life, passion, death, and resurrection. So her son's later life, passion, death, and resurrection, and her role in that series of events, are already a part of her own causal history. For her to freely choose not to assent to God's plan would be to contradict some fact that is already true of her: that she has been redeemed by her son's life, passion, death, and resurrection. For her to freely choose not to assent to God's plan would be akin to the time-traveler going back in time and killing her own grandfather in his youth. It simply cannot be done. And so it seems that Mary is not free to refrain from assenting to God's plan for her. There are no possible courses of action available to her at the annunciation other than her fiat. Her response to the angel Gabriel's invitation has, in a sense, already been written.

In the immaculate conception causal time loop, the later decisions and actions of Mary's son, Jesus Christ, are also fixed by the loop in at least the same way as Mary's. For example, in the agony in the garden, when Christ prays to the Father and agonizes over the cost of his participation in His Father's plan, it is no more open to Him to freely choose not to assent to His Father's plan than it was for Mary to freely choose not to assent to the Father's plan for her. And for at least the same reason. For Christ has been born of Mary, who was immaculately conceived, and whose immaculate conception was caused by Christ's own life, passion, death, and resurrection-events which are, from the perspective of Christ in the garden at Gethsemane, future events. Even prior to His life, passion, death, and resurrection, those later events are already a part of Christ's own causal history. For Him to freely choose not to assent to his Father's plan would be to contradict some fact that is already true of Him: that He has redeemed, by his life, passion, death, and resurrection, His own mother in a way that has preserved her from inheriting original sin. And so, as with Mary at the annunciation, there appear to be no alternative possibilities available to Jesus Christ in His agony in the garden. His acceptance of His Father's mission for Him in that scene is also already set.

My reply to this concern is similar in structure to my reply to the first. I admit that by granting the existence of causal time loops one does seem to be committed to rejecting the existence of real alternative possibilities for entities that exist within them, and by understanding the immaculate conception as a sort of causal time loop, this will commit those who adhere to this doctrine to the rejection of the principle of alternative possibilities. But I would also like to suggest that this too is something to which those who do hold or would hold such a doctrine may already be committed. Anyone who does or would hold the doctrine of the immaculate conception probably already has other reasons to reject the claim that free will requires alternative possibilities at the moment of decision. For example, anyone who is already committed to the claim that God has infallible foreknowledge would seem to be committed to the claim that all future events will in fact occur as God foreknows them. All future events, including the future events that involve the actions and decisions of 
causal agents, will in fact take place as God foreknows them. They cannot be otherwise. No causal agent can perform any action other than those actions that God foreknows that he or she will perform. And so in a very real sense, if God has infallible foreknowledge, then there are no alternative possibilities available to any causal agent at the moment of decision. The causal agent will in fact act as God foreknows that he or she will and that agent can in no way act otherwise. Nevertheless, many of those committed to the claim that God has infallible foreknowledge and that, thus, there are no real alternative possibilities available to us in our decisions, also hold that this is consistent with at least some causal agents freely choosing to perform the actions that God foreknows that he or she will perform. ${ }^{12}$ How precisely a causal agent's freedom can be made compatible with God's infallible foreknowledge need not be settled here, but the fact that many philosophers think that these two claims are compatible is evidence that such philosophers are already thinking of freedom without alternative possibilities.

There may also be other theological cases outside of the immaculate conception and God's eternal foreknowledge that might push the committed Christian to a rejection of the principle of alternative possibilities as well. For example, many Christians hold that the blessed in heaven freely choose to love God, even though it is no longer possible for them to fail to do so. ${ }^{13}$ The case of prophecy also seems to push us in the direction of rejecting the principle of alternative possibilities. For example, when Jesus prophesizes that Judas will betray him, it is no longer possible for Judas to freely refrain from doing so (lest Jesus's prophecy turn out to be false), and yet Christians believe that when Judas does betray Jesus, his act is a grave sin, freely committed. ${ }^{14}$ There is also, once again, the case of Christ's agony in the garden. It is held by many Christians that in the garden at Gethsemane, Christ's human nature freely chooses to assent to the Father's plan for him, even though Christ's human will and His divine will can never in fact conflict. ${ }^{15}$ Now, it is certainly available to the committed Christian to deny that these particular cases do actually involve a violation of the principle of alternative possibilities, but what I think that these cases show is that it is likely that anyone committed to the doctrine of the immaculate conception already has several reasons to reject the necessity of alternative possibilities for free choice, and so such a person is unlikely to find the implication that understanding the immaculate conception as a sort of causal time loop forces him or her to reject the principle of alternative possibilities especially alarming or concerning. In whatever way he or she understands the nature of free will, it is likely that he or she is already committed to a conception of human freedom that does not require alternative possibilities.

\footnotetext{
${ }^{12}$ Classic examples of this sort of position include Augustine (1993, Book Three) and Boethius (1999, Book Five). Contemporary examples of this sort of position include Stump and Kretzmann (1991), Zagzebski (1991, 1997), Hunt $(1999,2003)$.

${ }^{13}$ For discussion, see, for example, Pawl and Timpe $(2009,2013)$, Cowan (2011), and Timpe (2014, Chapter 6).

${ }^{14}$ Dante, for example, famously places Judas at the very bottom of hell for his betrayal of Christ (Dante 2003, Canto XXXIV).

${ }^{15}$ For discussion, see, for example, Pawl and Timpe (2016) and Pawl (2019, Chapters 5 and 8).
} 


\section{Insufficient Explanations: Circular and Otherwise}

The third concern that I would like to consider here is a bit more difficult to pin down, but generally the problem is this: in causal time loops, the explanations given, and indeed, the only explanations that can be given, for the occurrence of the events that exist within them are necessarily circular, and circular explanations, if not outright inadmissible, seem to many to be inadequate or unsatisfying or incomplete in some way.

In order to concentrate and exhibit the full force of this objection, let us consider two particular types of causal time loops: object loops and information loops. An object loop is a state of affairs in which some object exists entirely within a single causal time loop. ${ }^{16}$ For example, imagine that a young man is given a pocket watch in his youth by a stranger at a train station. ${ }^{17}$ The young man carries this pocket watch with him as he grows older and as an adult this young man comes to invent a time machine. The young man, now an old man, travels back in time by means of the time machine that he has invented, returns to the train station at which he was present when he was young, and gives the pocket watch to his younger self, telling him to take very special care of this watch, since someday it will play an important role in a later event in his life. Note the causal loop here. The young man receives the pocket watch as a young man, carries it with him over the course of his life, and then, as an old man, travels back in time to pass on the pocket watch to his younger self. How did the young man get the pocket watch? It was given to him by his older self. But where did his older self get the pocket watch? He received it years ago from the stranger at the train station, which turned out to be an older version of himself. The pocket watch in this story exists entirely within the causal time loop. The watch is found nowhere outside of it. Because it exists entirely within the causal time loop, the pocket watch has no beginning of existence. It was never made by anyone in a shop, was never sold, and was never purchased. This is what is so curious about object loops. They can incorporate unmade artifacts. ${ }^{18}$

A second particular type of causal time loop is an information loop. An information loop is a state of affairs in which some piece of information exists entirely within a single causal time loop. ${ }^{19}$ For example, imagine that as a young woman, Melanie receives a strange letter in her mailbox, which includes precise details on how to build and operate a time machine. Imagine that several years later, Melanie uses these instructions to successfully build this time machine. She then travels back

\footnotetext{
${ }^{16}$ Objects loops are discussed in Macbeath (1982, 415-417), Hanley (2004, 131-135), Wasserman (2018, 157-165).

${ }^{17}$ A similar scenario, also involving a pocket watch, serves as the basis for the plot of the 1980 film, Somewhere in Time.

${ }^{18}$ As several authors have pointed out, in order for an object loop to work, it would need to be the case that the object in question either undergoes no intrinsic change at any point in the story or is such that it is completely restored prior to being sent back in time. Otherwise, the object would possess inconsistent features in successive narrations of the story. For more on the "restoration problem" or "restoration paradox" for object loops, see, for example, Macbeath $(1982,417)$, Hanley $(2004,133$ $135)$, and Wasserman $(2018,163-165)$.

${ }^{19}$ Information loops are discussed in Lewis $(1976,149)$, Macbeath $(1982,415-417)$, and Hanley $(2004$, 135-142).
} 
in time, where she writes down on a piece of paper precisely how she was able to construct and operate the time machine. She then places this piece of paper in an envelope and places the envelope in the mailbox of her younger self, so that she will know how to do it when she gets older. ${ }^{20}$ Note the causal loop here. Melanie receives instructions on how to build a time machine, builds that time machine, and then travels back in time to instruct her younger self on how she did it. How did the younger Melanie learn how to build a time machine? From the instructions placed in her mailbox by her older self. But where did her older self learn how to build a time machine? From the instructions that she found in her mailbox when she was younger, placed there by her older self. The information about how to build and operate a time machine exists entirely within this loop. The information is found nowhere outside of it. And because it exists entirely within the causal time loop, the knowledge of how to build the time machine has no origin and no beginning of existence. It was never intuited, it was never discovered, it was never calculated, it was never thought of for the first time. This is what is so curious about information loops. They can incorporate information learned or discovered from nowhere by no one. ${ }^{21}$

The point that I think is most forcefully captured by both object loops and information loops is that there seems to be something deeply unsatisfying or incomplete about the explanations given for objects and events that exist or occur entirely within causal time loops. Yes, the younger man's possession of the pocket watch can be explained by his having been given it by his older self, and yes his older self's possession of the pocket watch can be explained by his having been given it as a young man, but something still seems inadequate or incomplete about this explanation. It seems that we want to demand of the pocket watch (and of the instructions for how to build a time machine) a further explanation of its existence: where did the watch come from in the first place? How did it get into the loop? Why does that particular object or set of instructions exist at all and why does it have the particular features that it does?

The first thing to note here is that the first and second of these questions, the questions concerning where the object or information came from in the first place and how it got into the loop, while they might seem like the right questions to ask, are actually improperly formulated. Objects and pieces of information that exist entirely within causal time loops have no beginning of their existence and have never existed anywhere outside of the particular causal loops in which they are found. That's the whole point. And so it cannot be asked of such objects or pieces of information where they came from in the first place or how they got into the loop, since there is no first place, and there is no time at which they ever existed outside of the loop.

And yet something still seems inadequate or incomplete about the explanations given for the occurrence or existence of events or objects in causal time loops. What is the source of this lingering dissatisfaction? I would like to propose that the lingering unease or dissatisfaction that many feel with respect to causal time

\footnotetext{
${ }^{20}$ Similar stories, in which the information that is passed on is the information on how to build a time machine, are described in Lewis $(1976,149)$, Harrison $(1979,65)$, and Macbeath $(1982,398-399)$.

${ }^{21}$ Notice that because an information loop need not involve any single looping object, information loops are not susceptible to the restoration problem. (See Hanley $(2004,137)$ for more on this.)
} 
loops points to a deeper unease or dissatisfaction that many have with explanations for the existence or occurrence of contingent and seemingly arbitrary objects, events, or states of affairs solely in terms of other contingent and seemingly arbitrary objects, events, or states of affairs. And I think that this deeper unease or dissatisfaction is most closely captured by the third question raised above, that which asks why the particular object or piece of information that is present in some causal time loop exists at all and has the particular features that it does. What I think that causal time loops nicely illustrate is that contingent states of affairs generally seem to many to not provide a sufficient explanation for their own existence, nor do any of the events or objects that occur or exist within them seem to many to provide a sufficient explanation for the occurrence or existence of any of the others. The thrust of contingency arguments for the existence of God is that the existence of any contingent state of affairs cannot be sufficiently explained solely by means of the contingent beings found within it (or any contingent being at all, for that matter). ${ }^{22}$ According to such arguments, there must be some further explanation outside of any contingent state of affairs, something that answers not only why these particular events occurred but why any of these contingent events or objects exist at all. Now, if one does find the sorts of explanations that are usually given for objects or events that exist or occur with causal time loops dissatisfying, ${ }^{23}$ I think that what he or she is really uneasy

\footnotetext{
${ }^{22}$ See, for example, Reichenbach (2019) and O'Connor (2008).

${ }^{23}$ And, importantly, not all who have seriously thought about such cases do. In his $(1976,149)$, for example, Lewis remarks, concerning his own example of an information loop, "But where did the information come from in the first place? Why did the whole affair happen? There is simply no answer. The parts of the loop are explicable, the whole of it is not. Strange! But not impossible, and not too different from inexplicabilities we are already inured to. Almost everyone agrees that God, or the Big Bang, or the entire infinite past of the universe, or the decay of a tritium atom, is un? caused and inexplicable. Then if these are possible, why not also the inexplicable causal loops that arise in time travel?" In assessing a similar case, Levin remarks, "how did it get started and who wrote the book about building a time machine? However, these questions are no different than questions about where anything came from. We can ask about the origin of the atoms that make up Jocasta; their time line is not neatly presented to us. The atoms either go back endlessly, or if the universe is finite, they just start. In either case the question of ultimate origin is as unanswerable as the question of the book's origin. What makes us think that when such questions are asked about the loop they are different and ought to be answerable is that the entire loop is open to inspection. Sub specie aeternitatis this difference disappears" $(1980,70)$. And in his $(2012,263)$, Meyer remarks, "Causal loops thus admit all the explanation one can reasonably ask for. If the laws of nature cooperate then the events that make up a loop can be explained causally. To ask for more, and to request a 'full' explanation of causal loops, is to ask for something that is impossible. In this case, the blame would fall on the person asking the question, not on our inability to answer it. Causal loops are no more mysterious than infinitely descending causal chains." So not all who have seriously thought about causal loops have thought that there is anything insufficient or incomplete about the explanations given for the objects and events that exist and occur within them. But what is telling about these authors, I think, is that each of them also finds nothing problematic about causal explanations of other contingent and seemingly arbitrary objects, events, or states of affairs solely in terms of other contingent objects, events or state of affairs. According to these authors, the explanations given for objects and events that exist and occur within causal time loops are no more problematic about the explanations given for other contingent objects, events, or states of affairs in terms of other contingent objects, events, and states of affairs. And on this point, I am entirely in agreement with these authors. My point here is just that if someone finds the sorts of explanations for the former problematic, she should also find the sorts of explanations for the latter problematic.
} 
about are explanations of contingent objects, events, or states of affairs that involve only other contingent objects, events, or states of affairs. As with other contingent states of affairs, what such a person is asking for is something existing outside of the causal time loop in question, something that can offer a complete and sufficient explanation for the events and objects that occur within that loop.

If I am right to suggest that what is going on here is that those dissatisfied with explanations given within causal time loops are thinking that a sufficient explanation for the existence of any causal time loop and any of the objects or events that exist or occur within it would have to posit something outside of itself, notice that anyone who accepts the doctrine of the immaculate conception already thinks that there is something outside of this particular loop, and indeed outside of any contingent states of affairs, that explains the existence of the loop and everything contained within it: God. And so I do not think that the fact that causal time loops and the objects or events that exist or occur within them call out for further explanation should be seen as alarming or concerning for anyone who does or would accept the doctrine of the immaculate conception. For he or she is already committed to there being such a further explanation. In any particular causal time loop, as in any contingent state of affairs, God is the ultimate causal explanation for why the objects and events contained within it exist at all and have the particular features that they do.

\section{No Respect for Fundamental Principles of Causality}

The final philosophical concern for causal time loops that I would like to consider is that, while they may be logically consistent, causal time loops should be taken to be impossible because they violate some fundamental principle of causality. I can think of two fundamental principles of causality that might be threatened by causal time loops: (1) that nothing can be the cause of itself and (2) that a cause must be prior to its effect. ${ }^{24}$ Let us begin with principle (1). Principle (1) seems to be violated by causal time loops because in a causal time loop it is possible for some person or thing to be the cause of its own existence. For example, in our introduction we described two cases in which this appears to be true, one involving direct causal relations and one involving indirect causal relations. In the first, we imagined that someone might travel back in time and perform certain actions such that one turns out to be, as a result of those actions, one's own mother or father. In the second, we imagined that someone might travel back in time and perform certain actions which cause one's own parents to meet and fall in love, which causes them to later marry, which causes them to later conceive the child who will eventually travel back in time. Indeed, in the second general type of causal time loop, the one in which the whole of time loops back on itself, every event and every object is at least a partial indirect cause of its own existence. And in the case of the immaculate conception, there is a

\footnotetext{
${ }^{24}$ While I have listed these principles of causality as two separate principles, they may actually be more closely related to one another. Thomas Aquinas, for example, insists on (1) because he thinks it follows from (2) (see Aquinas (1948, I, Q. 2, A. 3, Co.) There may be other reasons to think that we should hold (1) independent from considerations in favor of (2), or there may be reasons to think that we should hold (2) and not (1), however, and so here I have treated them as separate issues.
} 
sense in which the event of Christ's redemption of fallen humanity causes itself to occur by means of the earlier immaculate conception of Mary. ${ }^{25}$ In the case of the immaculate conception, it even seems true to say that Christ (in His human nature) is in some sense the cause of His own existence (of His human nature), once again, indirectly, by means of the immaculate conception of His mother. It seems, then, that in light of these possibilities introduced by granting the possibility of causal time loops, the fundamental causal principle that nothing can be the cause of itself is violated, and for that reason we should think that such causal time loops are impossible.

Principle (2) seems to be violated by causal time loops because in a causal time loop there is at least one cause that is not prior but posterior to its effect. For, by definition, a causal time loop is a state of affairs in which some later event is at least a partial cause of some earlier event, which is also at least a partial cause of it. By definition, then, a causal time loop is a state of affairs in which at least one cause is temporally posterior to its effect and at least one effect is temporally prior to its cause. In the case of the immaculate conception, Christ's redemption of fallen humanity by means of His life, passion, death, and resurrection is the cause of Mary's immaculate conception, but it also takes places after the immaculate conception has occurred. And so Christ's redemption of fallen humanity is an event that takes place after its effect. And that effect, the immaculate conception, is an event that takes places prior to its cause.

Is there anyway to admit the possibility of causal time loops while still preserving these two fundamental causal principles? One way of resolving the apparent conflict between causal time loops and the first causal principle would be to reformulate that principle in a way that still captures its primary intent. ${ }^{26}$ The first proposed revision to the causal principle is as follows: nothing can be the cause of its own existence at the same time that it is caused to exist. By formulating the causal principle in this way, it allows us to preserve the first causal principle in any causal time loops that involve indirect causal relations. For, in those causal time loops that involve indirect causal relations, the person or event that causes itself to exist does so through a temporally-extended causal series. For example, when the time-traveler travels back in time and causes her own parents to meet and fall in love, she has at that point made her causal contribution to the series, and it is only later that this culminates in her own birth.

It is less clear how this proposed revision to the first causal principle is preserved in causal time loops that involve direct causal relations, however. For in those cases it looks like the person or event does indeed cause itself to exist at the same time that it is caused to exist. The key to preserving this revised version of the

\footnotetext{
${ }^{25}$ Though, as one reviewer has helpfully pointed out, the bootstrapping involved here appears only at the surface. True, the later event does cause the earlier event which in turn causes it, and so, in a sense, by transitivity, the later event is a cause of itself. But God is also the primary or ultimate cause of both Christ's redemption of fallen humanity and Mary's immaculate conception, and so, at a deeper level of analysis, what happens here is that God causes the earlier event by means of the later event, and the earlier event by means of the later event.

${ }^{26}$ This is similar to the strategy pursued by Macbeath in his (1982) in trying to preserve similar principles.
} 
first causal principle even in cases of direct causal relations is to distinguish between two different measures of time. Following David Lewis, in discussions of time travel, it is standard to distinguish between external time and personal time (Lewis 1976, 146). External time is the measure of time along the universe's own linear timeline. It is the measure of time by which we ordinarily date events in history. Personal time, on the other hand, is the measure of time along a time-traveler's own personal timeline. It is the measure of how much time has passed in that person's own life and the ordering of events in that person's life from that person's perspective. So, for example, imagine that someone were to, at precisely 10:00am, travel back in time to 9:45am on the same day. At 10:01am, one minute will have passed in external time since she went back in time, but for the time-traveler, sixteen minutes will have passed. ${ }^{27}$ Moreover, according to external time, the event of the time-traveler's appearing at 9:45am occurs before the event of her traveling back in time, but, of course, from the time-traveler's perspective, that is, according to personal time, the order of these events is reversed. Now imagine that this same time-traveler were to travel back in time to ten months before she was born and perform certain actions such that as a result of those actions she turns out to be her own mother. The timetraveler is the cause of her own existence, and, according to external time, she is the cause of her own existence at the same time that she is caused to exist. However, according to personal time, the cause and effect are not temporally contiguous. According to personal time, the time-traveler causes herself to exist several years after she is caused to exist. And thus on at least one measure of time, the reformulated first causal principle is preserved.

Now, in the case of the immaculate conception, the causal relations between the two events in question are indirect. Christ's redemption of fallen humanity through His life, passion, death, and resurrection is the cause of Mary's immaculate conception, but the immaculate conception is the cause of Christ's later redemption of fallen humanity only through a temporally-extended causal series. There are several events that occur between the two. And so, as a result, even though Christ's redemption of fallen humanity does, in some sense, cause itself to exist, it is not the direct cause of its own existence. It does not cause itself to exist at the same time that it is caused to exist. And so the reformulated version of the first causal principle is preserved.

A second possible revision to the first causal principle that would allow it to be preserved in causal time loops is as follows: nothing can be the complete cause of its own existence. When understood this way, I think that causal time loops pose no problem for the principle. While it is true that in a causal time loop a single person can cause her own existence by travelling back in time and causing, at an earlier time, some event in her own causal history, one of the key lessons from our discussion of the third philosophical concern for causal time loops above is that there seems to

\footnotetext{
${ }^{27}$ So, for example, at the end of Avengers: Endgame, Steve Rogers (Captain America) time-travels from the year 2023 back to 1940something and lives out the rest of his life there. In 2023, moments after being sent back, a much older Steve Rogers is found sitting on a bench near the spot at which he was sent back. For the characters who sent him back, that is, from the perspective of external time, only a few moments have passed since he was sent back, but from Steve Rogers' perspective, that is, from the perspective of his personal time, several decades have passed since that moment.
} 
many to be something incomplete about the explanation given for the person's later existence in terms of the person's earlier action. The way that I diagnosed the dissatisfaction that many feel about explanations within causal time loops is as an instance of a larger dissatisfaction with explanations of contingent states of affairs solely in terms of the contingent entities found within them. As I explained earlier, the thrust of contingency arguments for the existence of God is that the existence of any contingent state of affairs cannot be sufficiently explained solely by means of the contingent beings found within it (or any contingent being at all, for that matter). It seems to many that there must be some further explanation outside of that contingent state of affairs, something that answers not only why these particular events occurred but why any of these contingent events or objects exist at all. The sense here is that without answering this further question we have not given a complete explanation for the existence of these contingent beings or the contingent state of affairs in which they are found. Pertaining to the present issue, what I think a proponent of the possibility of causal time loops can say is that even in a causal time loop nothing is a complete cause of itself, nothing is a complete cause of its own existence. And the reason for this is that the entities in these causal time loops are themselves contingent beings, requiring a cause beyond themselves for a sufficient explanation of their existence.

The second fundamental causal principle, that which says that a cause must be prior to its effect, is a bit trickier to preserve in the case of causal time loops. But one way to preserve a version of this principle would be to distinguish between varieties of causal priority. One of the ways in which a cause can be prior to its effect is that it can be prior in time. And it does seem that the primary intent of the second fundamental causal principle has this sort of priority in mind. It does seem to be meant to exclude the possibility of some cause occurring after its effect. But there are other ways in which a cause can be prior to its effect as well. And by opening up the causal principle to include these other forms of causal priority, we can preserve this principle in the case of causal time loops. In addition to being temporally prior to its effect, a cause can also be ontologically prior to its effect, in that it holds or suspends that effect in existence, or explanatorily prior to that effect, in that it serves as the primary explanation for the existence of that effect. And these varieties of causal priority can in principle come apart. A cause can fail to be prior to its effect in one way, or even be posterior to its effect in that way, while also remaining prior to its effect in one of the other ways. This can be shown, for example, through Aristotelian causes. Final causes, for example, are posterior to their effects in time, but still explanatorily prior to them. On an Aristotelian picture of the world, particular organisms have many of the particular features that they do because they are directed to particular ends. And it is also a feature of Aristotelian causality that in material substances formal causality and material causality are causally complementary. On an Aristotelian picture of the world, the substantial form of a material substance is the formal cause of the matter and the matter is the material cause of the substantial form. ${ }^{28}$ The matter has certain features that it does because of the substantial form that inheres in it, and the substantial form is the particular substantial form that it is

${ }^{28}$ See, for example, Aquinas (2014, Chapter Four). 
because of the matter that it enforms. Importantly, in such case neither the form nor the matter is temporally prior to the other. Both are causes of one another at the same time. Granted, only in the case of final causality do we have a cause occurring some time after its effect, but what this shows is that it is not unprecedented to suggest that a cause can fail to be prior to its effect in one way as long as it is prior to that effect in some other way. Now, this is not to say that in order to account for causal time loops, one must be committed to the reality of Aristotle's four causes. But what I do think this brief discussion shows is that in at least one theory of causality that insists on the two aforementioned fundamental causal principles it is plausible to suggest that it is possible for a cause to fail to be temporally prior to its effect, as long as it is prior to its effect in some other way.

Will this proposal help us in the case of the immaculate conception? I think so. As we have seen, the immaculate conception, the event in which Mary is preserved from the stain of original sin, and the cause of Christ's later redemption of fallen humanity by means of His life, passion, death, and resurrection, is indeed temporally prior to its effect. But Christ's redemption of fallen humanity, the cause of Mary's immaculate conception, is temporally posterior to its own effect. However, while Christ's later redemption of fallen humanity by means of His life, passion, death, and resurrection is temporally posterior to the immaculate conception, there may also be a sense in which it is explanatorily prior. For it seems that Christ's redemption of fallen humanity is the more important of the two events. It seems that Christ's redemption of fallen humanity is the event that God most desires to occur, that which is most essential to His plan for our salvation. And God sees that it is most fitting to bring about that event by means of the earlier immaculate conception. If this is right, then there may be a sense in which the immaculate conception, while temporally prior to Christ's redemption of fallen humanity, is explanatorily posterior to it, in the sense that the immaculate conception takes place for the sake of Christ's redemption of fallen humanity. In such case, both events would be prior to their effects, that is, to each other, but in different ways.

So perhaps there are ways of preserving these two fundamental causal principles, or modified versions of them, while still granting the possibility of causal time loops. Or maybe there is a different lesson to be learned here. Maybe causal time loops do show that these two causal principles have possible exceptions and so are not universally true. ${ }^{29}$ Maybe what we learn from thinking about causal time loops is that some apparently basic or fundamental metaphysical principles are not as basic or fundamental as we previously thought. Indeed, some philosophers think that the possibility of backwards time travel reveals to us that other apparently logical principles, such as the principle that nothing can be wholly located at two places at once, ${ }^{30}$ or the principle that a composite whole cannot have just one proper part ${ }^{31}$ could have exceptions. Perhaps here too causal time loops are an important exception to what would otherwise appear to be fundamental metaphysical principles.

\footnotetext{
${ }^{29}$ This is precisely what Wasserman concludes, for example, in his $(2018,150,154-157)$.

${ }^{30}$ See, for example, Miller (2006), Wright (2006), Gilmore (2007), and Pickup (2015).

${ }^{31}$ See, for example, Effingham and Robson (2007), Smith (2009), Effingham (2010), Gilmore (2007), and Kleinschmidt (2015).
} 


\section{Conclusion}

In this paper, I have argued in support of two conclusions. First, I have argued that anyone who is committed to the dogma of the immaculate conception is also committed to the possibility, and, indeed, the actuality, of at least one causal time loop. Second, I have also argued that the fact that the immaculate conception is a kind of causal time loop is no reason to reject the dogma, since, as I have tried to show, all of the major worries for causal time loops can be resolved in one way or another. Admittedly, the sort of objection to the immaculate conception that I have explored in this paper is a rather obscure one. I know of no one who has explicitly argued from the impossibility or implausibility of causal time loops to the impossibility or implausibility of the immaculate conception. But I do think that reflecting upon some of the major concerns that have been raised for causal time loops may help to relieve some of the deeper philosophical worries that one might have about this miraculous series of events that is purported by Roman Catholics and other Christians to have occurred. $^{32,33}$

\footnotetext{
${ }^{32}$ Roman Catholics, and Christians more generally, might be committed to the actual existence of other causal time loops as well. So, for example, if petitionary prayer for past events is possible, then this could potentially introduce several causal time loops throughout history. It has also been suggested to me that Christians may be committed to the claim that several key characters in salvation history who predate Christ are made virtuous and able to carry out their roles through retroactive application of sanctifying grace, made possible by Christ's later redemption of fallen humanity by means of His life, passion, death, and resurrection. In that case, maybe it is not simply for the sake of understanding the immaculate conception that Christians need to wrestle with causal time loops.

${ }^{33}$ I would like to thank audiences at the University of Mary and the 2019 Central Regional Meeting of the Society for Christian Philosophers at Hope College for helpful comments on earlier drafts of this paper.
} 


\section{References}

Alighieri, Dante. 2003. The Inferno. In The Divine Comedy, translated by John Ciardi. New American Library.

Aquinas, Thomas. 1948. Summa Theologiae, translated by the Fathers of the English Dominican Province. Benziger Bros. 2014. De Principiis Naturae, translated by Eleonore Stump and Stephen Chanderbhan. In Aquinas: Basic Works, edited by Jeffrey Hause and Robert Pasnau. Hackett.

Augustine. 2003. On Free Choice of the Will, translated and edited by Thomas Williams. Hackett.

Boethius. 1999. The Consolation of Philosophy, translated and edited by P.G. Walsh. Oxford University Press.

Catholic Church. 1997. The Catechism of the Catholic Church, Second Edition. Libreria Editrice Vaticana.

Cowan, Steven. 2011. "Compatibilism and the Sinlessness of the Redeemed in Heaven." Faith and Philosophy, 28 (4): 416-431.

Effingham, Nikk and Jon Robson. 2007. "A Mereological Challenge to Endurantism." Australasian Journal of Philosophy, 85 (4): 633-640.

Effingham, Nikk. 2010. "Mereological Explanation and Time Travel." Australasian Journal of Philosophy, 88 (2): 333-345.

Gilmore, Cody. 2007. "Time Travel, Coinciding Objects, and Persistence." Oxford Studies in Metaphysics, 3: 177-198.

Hanley, Richard. 2004. "No End in Sight: Causal Loops in Philosophy, Physics, and Fiction." Synthese, 141 (1): 123-152.

Harrison, Jonathan. 1979. “Analysis 'Problem’ No. 18.” Analysis 39 (2): 65.

Heinlein, Robert A. 1999. “-All You Zombies-.” In The Fantasies of Robert A. Heinlein. Tom Doherty.

Hunt, David. 2003. "Freedom, Foreknowledge, and Frankfurt." In Moral Responsibility and Alternative Possibilities edited by David Widerker and Michael McKenna. Ashgate.

Hunt, David. 1999. “On Augustine’s Way Out.” Faith and Philosophy, 16 (1): 3-26.

Kleinschmidt, Shieva. 2015. "Fundamentality and Time Travel.” Thought, 4 (1): 46-51.

Levin, Margarita R. 1980. "Swords' Points." Analysis 40 (2): 69-70.

Lewis, David. 1976. “The Paradoxes of Time Travel.” American Philosophical Quarterly, 13 (2): 145-152.

Macbeath, Murray. 1982. “Who Was Dr. Who’s Father?” Synthese, 51 (3): 397-430. 
Meyer, Ulrich. 2012. “Explaining Causal Loops.” Analysis, 71 (2): 259-264.

Miller, Kristie. 2006. "Travelling in Time: How to Wholly Exist in Two Places at the Same Time." Canadian Journal of Philosophy, 36 (3): 309-344.

Nahin, Paul J. 2017. Time Machine Tales: The Science Fiction Adventures and Philosophical Puzzles of Time Travel. Springer.

O'Connor, Timothy. 2008. Theism and Ultimate Explanation: The Necessary Shape of Contingency. Wiley-Blackwell.

Ott, Ludwig. 1992. Fundamentals of Catholic Dogma. Tan Books.

Pawl, Timothy and Kevin Timpe. 2016. "Freedom and the Incarnation." Philosophy Compass, 11 (11): 743-756.20

Pawl, Timothy and Kevin Timpe. 2009. "Incompatiblism, Sin, and Free Will in Heaven." Faith and Philosophy, 26 (4): 398-419. . 2013. "Heavenly Freedom: A Reply to Cowan." Faith and Philosophy, 30 (2): 396417.

Pawl, Timothy. 2019. In Defense of Extended Conciliar Christology. Oxford University Press.

Pickup, Martin. 2015. "Real Presence in the Eucharist and Time Travel." Religious Studies, 51 (3): 379-389.

Pope Pius IX. 1854. Ineffabilis Deus. The Holy See.

Pruss, Alexander. "Grace and Theories of Time." Available at http://alexanderpruss.blogspot.com/2019/06/grace-and-theories-of-time.html (Jun., 2019).

Rea, Michael C. 2015. “Time Travellers Are Not Free.” The Journal of Philosophy, 112 (5): 266-279.

Reichenbach, Bruce. 2019. “Cosmological Argument." In The Stanford Encyclopedia of Philosophy (Spring 2019 Edition), edited by Edward N. Zalta. $<$ https://plato.stanford.edu/entries/cosmological-argument/>.

Smith, Donald. 2009. "Mereology Without Weak Supplementation." Australasian Journal of Philosophy, 87 (3): 505-511.

Smith, Nicholas J. J. 2018. “Time Travel." In The Stanford Encyclopedia of Philosophy (Summer 2018 Edition), edited by Edward N. Zalta. <https://plato.stanford.edu/archives/sum2018/entries /time-travel/>.

Stump, Eleonore and Norman Kretzmann. 1991. "Prophecy, Past Truth, and Eternity." Philosophical Perspectives, 5: 395-424.

Stump, Eleonore. 2003. Aquinas. Routledge.

Timpe, Kevin. 2014. Free Will in Philosophical Theology. Bloomsbury.

Wasserman, Ryan. 2018. Paradoxes of Time Travel. Oxford University Press. 
Wright, John. 2006. "Personal Identity, Fission, and Time Travel." Philosophia, 34 (2): 129142.

Zagzebski, Linda. 1991. The Dilemma of Freedom and Foreknowledge. Oxford University Press.

1997. "Foreknowledge and Human Freedom." In A Companion to Philosophy of Religion, edited by Philip Quinn and Charles Taliaferro. Blackwell. 